\title{
UNSUR-UNSUR EKOLOGI DALAM SASTRA LISAN MANTRA PENGOBATAN SAKIT GIGI MASYARAKAT KELURAHAN KURANJI
}

\author{
Iswadi Bahardur*, Suryo Ediyono \\ Pendidikan Bahasa Indonesia, Fakultas Pascasarjana UNS
}

\section{A R T I K E L}

Kata Kunci:

Budaya

Ekokritik

Mantra

Nature

Nurture

Sakit gigi

\section{A RT I C LE INFO}

\section{Keywords:}

Culture

Ecocritic

Mantra

Nature

Nurture

Toothache

\begin{abstract}
A B S T R A K
Sastra sebagai bagian dari representasi kehidupan manusia selalu terikat dengan kultur dan lingkungan manusia. Permasalahan yang disampaikan oleh sastrawan dalam karya sastra merupakan bagian dari kenyataan yang terjadi di lingkungan tempatnya berada. Tidak terkecuali dengan sastra lisan. Sebagai sebuah genre sastra tradisional, sastra lisan memiliki ketergantungan dengan unsur-unsur ekologi yang terdapat di dalam alam semesta. Tumbuh-tumbuhan dan hewan, misalnya memiliki peran dalam konteks pembacaan teks-teks mantra saat proses pengobatan penyakit dilakukan oleh seorang dukun. Sastra lisan mantra pengobatan sakit gigi pada masyarakat Belimbing kelurahan Kuranji Kecamatan Kuranji kotamadya Padang, misalnya, dalam praktiknya oleh dukun selalu melibatkan unsur ekologi. Melalui kajian perspektif ekokritik dapat diketahui kehadiran sastra lisan mantra pengobatan sakit gigi pada masyarakat setempat dilatari oleh persyaratan pelengkap yaitu daun-daunan cocok bebek, air putih, sirih, gambir, kapur sirih, buah pinang, batang muda pohon pisang, daun beluntas, serta rokok. Keterlibatan unsur-unsur ekologi tersebut menunjukkan pencitraan yang kuat dari nature, nurture, dan culture masyarakat Belimbing.
\end{abstract}

\begin{abstract}
A B S T R A C T
Literature as part of the representation of human life is always tied to the culture and human environment. The problems presented by writers in literary works are part of the reality that occurred in the environment where he was. No exception to oral literature. As a genre of traditional literature, oral literature has a dependence on the ecological elements contained in the universe. Plants and animals, for example, have a role in the context of reciting the mantra texts when the treatment process of the disease is done by a shaman. Oral literature mantra treatment of toothache in community Belimbing kelurahan Kuranji Kecamatan Kuranji kotamadya Padang, for example, in practice by shaman always involves the element of ecology. Through the study of ecocritical perspective it can be seen that the presence of oral literature spells on dental treatment in local communities is supported by the complementary requirements of duck fruits, water, betel, gambier, whiting, betel nut, banana tree stems, beluntas leaves, and cigarettes. The involvement of these ecological elements shows a strong image of nature, nurture, and culture of Belimbing society.
\end{abstract}

\section{PENDAHULUAN}

Manusia dan alam memiliki hubungan ketergantungan satu sama lain. Manusia menjadi bagian dari organisme yang hidup di alam dan memanfaatkan berbagai unsur dan organisme lainnya yang terdapat di alam semesta. Sebagai bagian dari organisme alam, manusia tidak dapat hidup tanpa perbauran dan interaksi dengan organisme lainnya di lingkungan sekitarnya. Manusia membutuhkan alam atau lingkungan, baik lingkungan abiotik maupun lingkungan biotik. Tumbuh-tumbuhan, misalnya, menjadi sumber pangan utama bagi keberlangsungan kehidupan manusia.

${ }^{*}$ Corresponding author.

E-mail addresses: iswadi.bahardur@yahoo.co.id (Iswadi Bahardur), edisuryono@yahoo.com (Suryo Ediyono)

2579-3799/ @ 2017 BASINDO Journal. All rights reserved. This is an open access article under the CC BY license (http://creativecommons.org/licenses/BY/4.0/).

24 | BASINDO : Jurnal Kajian Bahasa, Sastra Indonesia, dan Pembelajarannya 
Sebagai bagian dari organisme lingkungan alam, manusia dituntut paham dengan berbagai gejala atau fenomena yang terjadi di alam. Manusia juga dituntut mampu menjaga keutuhan lingkungan alam dimana dia berada. Keberlangsungan ekosistem kehidupan manusia di alam sangat tergantung pada cara yang dilakukan dalam menjaga keseimbangan lingkungan alam. Perlakuan perlindungan segala macam organisme yang menghuni ekosistem lingkungan adalah bagian dari tanggung jawab manusia. Persentuhan dan interaksi manusia dengan alam pada akhirnya akan memberikan pengalam-pengalaman fisik dan batin yang membawa kesadaran akan pentingnya menjaga ekosistem bumi.

Ernst Bloch (dalam Kaswadi, 2015) menyatakan manusia memiliki pengalaman-pengalaman yang berkiat dengan lingkungan yang disebut dengan rangkaian antropological constans, yaitu dorongan-dorongan dan orientasi tetap manusia. Ada sekurang-kuangnya enam antropological constans yang bisa ditarik dari pengalaman sejarah manusia. (1) Relasi manusia dengan kejasmanian, alam, dan lingkungan ekologis. (2) Keterlibatan dengan sesama. (3) Keterikatan dengan struktur sosial dan institusi. (4) Ketergantungan masyarakat dan kebudayaan pada waktu dan tempat. (5) Hubungan timbal balik antara teori dan praksis. (6) Kesadaran relegius atau parareligius. Relasi manusia dengan kejasmanian, alam, dan lingkunga ekologis tersebut pada akhirnya yang akan membawa manusia pada sikap menghargai alam dengan beragam tindak serta keinginan untuk menjaga keutuhannya. Di samping keinginan menjaga dan merawat keutuhannya, relasi manusia dengan lingkungan ekologis juga disebabkan adanya kebutuhan untuk menghadirkan organisme alam sebagai penyeimbang, penyelamat atau untuk kesehatan.

Dilihat dari sejarah kehidupan manusia mulai dari kebudayaan tradisional, segala macam tradisi dan kultur yang dihasilkan manusia selalu merupakan hasil dari persentuhan dengan lingkungan alam. Sebagai contoh, sastra tradisi atau sastra klasik, khususnya sastra lisan, bersumber dari ritual-ritual dan tradisi yang dilakukan oleh manusia untuk menjaga keseimbangan kehidupannya. Dalam tradisi-tradisi-tradisi da ritual tersebut selalu melibatkan alam dengan segala macam organismenya. Tujuannya tidak lain adalah untuk menjaga keharmonisan antara manusia dengan ekosistem lainnya. Tradisi dan ritual tersebut kemudian menjadi bagian tidak terpisahkan dari tradisi sastra lisan dan folklore yang anonim. Dalam sejarahnya, sastra lisan dan folklore di nusantara bersumber dari berbagai tradisi dan ritual kuno yang melibatkan unsur-unsur alam dalam praktiknya. Awalnya tradisi-tradisi yang menjadi bagian sastra lisan dan folklore tersebut diciptakan adalah untuk menjaga keselamatan manusia dari berbagai kejadian alam seperti banjir, petir, hujan badai dan berbagai fenomena kerusakan alam lainnya. Dari tradisi tersebut berkembang tradisi lisan yang anonim dengan persentuhan berbagai karakter manusia sehingga melahirkan berbagai mitos tentang anak durhaka, kutukan menjadi batu, kutukan menjadi batu menangis, penjelmaan menjadi ikan duyung, dan lainnya.

Sastra lisan adalah salah satu genre sastra yang sangat erat keterkaitannya dengan alam sekitar tempat dimana diciptakan. Unsur-unsur sastra lisan selalu menghadirkan unsur alam sebagai pendukungnya. Kehadiran unsur-unsur alam dalam sastra lisan salah satu tujuannya adalah untuk mengatasi berbagai gejala alam yang ada kaitan dengan keberlangsungan hidup manusia dan falsafah penerimaan batin sebagai bagian dari alam dan lingkungnnya. Seperti halnya dinyatakan oleh Endraswara (2016: 20) sastra lisan menjadi saksi bahwa lingkungan alam sangat kondusif bagi kehidupan manusia. Banyak karya sastra lisan yang menggambarkan tentang kondisi alam yang luar biasa indah dan memanjakan kehidupan manusia dan telah menjadi darah daging bagi kehidupannya. Lebih lanjut Endraswara mencontohkan dari falsafah sastra lisan masyarakat Jawa, ana dina ana upa, manan ra manan sing penting kumpul. Ungkapan sastra lisan ini menurut Endraswara menggambarkan keterkaitan sikap manusia, nrimo dalam masyarakat Jawa terhadap kondisi sosial-ekonomi di alam semesta.

Satu diantara genre sastra lisan yang bersentuhan sangat akrab dengan lingkungan alam adalah mantra. Sebagai sebuah genre sastra terdahulu dan tradisional, kehadiran sastra lisan sangat terikat kuat dengan berbagai fenomena kejadian yang terjadi di alam sekitar. Sama halnya dengan ketergantungan manusia tradisional dengan berbagai unsur alam, sastra lisan telah mewakili keterikatan manusia dengan alam tersebut. Mantra sebagai satu diantara genre dari sastra lisan secara jelas telah merepresentasikan bagaimana keterikatan manusia dengan alam dan lingkungan dimana dia berada. Teks-teks mantra serta konteks pendukung yang melatarbelakangi kehadirannya menunjukkan bahwa unsur-unsur alam tertentu seperti tumbuhan, hewan, kondisi cuaca, waktu dan manusia itu sendiri selalu menjadi unsur pendukung kelahiran sebuah mantra.

Dilihat dari sejarah kelahirannya, sastra lisan mantra merupakan kesusastraan paling tua di nusantara di nusantara. Awal kelahirannya, mantra digunakan sebagai bagian dari ritual upacara tradisi untuk kepentingan tertentu seperti pengobatan orang yang sakit, melindungi diri dari kejahatan, bahkan untuk tujuan negatif. Dalam praktiknya, mantra biasanya dirapalkan secara lisan oleh orang-orang yang dianggap memiliki kekuatan supranatural, orang yang dipandang pintar, mantra yang dirapalkannya dipandang mempan untuk mengobati suatu penyakit tertentu.

Banyak mantra yang berkembang pada sastra lisan suku bangsa di Indonesia. Sebagai contoh di dalam etnis masyarakat Minangkabau, mantra telah berkembang sejak zaman tradisionla sampai ke zaman kekinian. Dalam rentang sejarah tersebut mantra bagi masyarakat Minangkabau memiliki fungsi yang sangat dekat dan melebur dalam kehidupan sehari-hari, misalnya mantra yang digunakan untuk melindungi (memagar) rumah dari bahaya unsur-unsur negatif, mantra untuk mengusir roh-roh jahat, mantra untuk pengobatan sakit, mantra untuk percinntaan, atau mantra untuk melindungi diri dari hal-hal negatif dan berbau hitam. Mantra-mantra tersebut berkembang di berbagai daerah Minangkabau dengan berbagai penamaan, struktur, aspek-aspek pendukung, konteks yang melatari kehadirannya, serta sosok perapal mantranya. Sebagai contoh dalam masyarakat di kecamatan Sutera Kabupaten Pesisir Selatan Sumatera Barat terdapat mantra yang dikenal dengan nama mantra Pamanih. Mantra Pamanih bagi masyarakat di Kecamatan Sutera dianggap memiliki kekuatan magis yang berfungsi mempercantik atau mempergagah diri si pemiliknya. Sampai saat dalam masyarakat di daerah ini mantra Pamanih masih dikenal meskipun praktik pemakaiannya sudah jarang karena adanya perubahan pola pikir dan pola pendidikan. Terlepas dari eksistensi tersebut, patut diketahui bahwa dalam praktiknya mantra Pamanih tidak terlepas dari pengaruh unsur-unsur makhluk hidup

25 | BASINDO : Jurnal Kajian Bahasa, Sastra Indonesia, dan Pembelajarannya 
yang terdapat di alam sekitar daerah tersebut. Konteks kehadiran mantra tersebut selalu didukung oleh ragam organisme tumbuh-tumbuhan dan hewan. Selain mantra Pamanih tersebut terdapat berbagai jenis mantra lain yang masih berkembang dalam sastra lisan di Minangkabau.

Terlepas dari berbagai fungsi dan ragam mantra tersebut, hal yang menarik untuk dikaji adalah dalam praktiknya mantra di dalam sastra lisan Minangkabau selalu bersinggungan dengan ekosistem yang terdapat di alam. Dari awal kajian-kajian terhadap mantra di daerah tersebut telah ditemukan kenyataan bahwa dalam bait-bait, lirik dan kalimat yang diucapkan oleh perapal mantra selalu mengandung maksud, tujuan, dan objek berupa benda-benda dan makhluk hidup yang terdapat di alam semesta. Hal ini memperkuat kenyataan bahwa dalam penciptaan sastra lisan mantra tersebut tergambar bagaimana hubungan dan saling ketergantungan antara manusia dengan segala komponen organisme yang terdapat dalam ekosistem alam.

Satu diantara mantra yang berkembang dalam masyarakat Minangkabau adalah mantra pengobatan sakit gigi. Berdasarkan hasil penelusuran dan penelitian penulis, mantra ini ternyata telah lahir dan berkembang dalam salah satu kelurahan di kota Padang yaitu kelurahan Kuranji, tepatnya di daerah Belimbing. Pelaku aktif dari mantra tersebut adalah dukun. Dalam masyarakat tradisional di daerah Belimbing seorang dukun dipercaya memiliki kekuatan sakti dan magis sehingga dapat mengobati sakit tertentu. Kekuatan tersebut dipercayai bersumber dari mantra yang dimiliki oleh sang dukun.

Sastra lisan mantra pengobatan sakit gigi pernah berkembang dan dipraktikkan untuk pengobatan sakit gigi sejak zaman tradisional sampai sekarang. Namun jika dibandingkan dengan zaman tradsional, intensitas keyakinan masyarakat daerah setempa terhadap mantra pengobatan sakit gigi sudah sangat berkurang dikarenakan kemajuan faktor pendidikan, kemajuan teknologi medis, serta status kesejahteraan ekonomi. Saat ini memang masih terdapat anggota masyarakat yang mempraktikkan pengobatan kepada duun yang memiliki mantra pengobat sakit gigi, namun hanya terbatas pada anggota masyarakat yang berada di pesolok Belimbing dan terbelakang dalam pendidikan. Selain mantra pengobatan sakit gigi, di daerah Belimbing juga terdapat kepercayaan pada mantra pengobat terkena gigitan binatang buas seperti ular, mantra pejinak bisa, mantra pasak lidah, mantra banaik rumah, dan mantra meneruka lahan pertanian baru.

Terlepas dari keberadaan mantra pengobatan sakit gigi di daerah Belimbing pada saat ini, hal lain yang penting untuk dikaji adalah keterlibatan unsur-unsur ekologi dalam praktik mantra tersebut. Praktik mantra pengobatan sakit gigi yang dilakukan oleh dukun di daerah setempat melibatkan berbagai tumbuh-tumbuhan dan unsur abiotik lainnya, seperti daun Cocor Bebek, daun Sirih, batang pohon Pisang, buah Pinang, kapur sirih, gambir, air putih, dan juga rokok. Bahan-bahan yang bersumber dari ekosistem alam tersebut digunakan sebagai syarat pelengkap dalam proses pengobatan sakit gigi dengan menggunakan mantra dukun. Keberadaan unsur-unsur ekologi dalam mantra pengobatan sakit gigi di daerah Belimbing tersebut adalah bagian penting dalam khasanah sastra lisan dan kaitannya dengan lingkungan hidup. Kenyataan keterlibatan unsur ekologi dalam sastra lisan mantra masyarakat setempat menegaskan bahwa dalam ekosistem kehidupannya terdapat interaksi antara nature (alam), nurture (pengalaman dan kebiasaan), dan culture (kebudayaan).

Secara teoretis, menurut Djamaris (2002:10), Amir (2013:67), mantra adalah puisi yang tertua dalam sastra Minangkabau yang bermakna doa atau permohonan, diciptakan untuk mendapatkan kekuatan gaib dan sakti, didaraskan seseorang pada tempat tertentu, teks dan lafalnya tidak jelas, kekuatan magis implisit di dalamnya, dan ada akibat riil atas pelaksanaannya.

Dalam mantra tercermin kepercayaan masyarakat pelakunya yaitu kepercayaan animisme dan dinamisme. Masyarakat tradisional percaya bahwa setiap benda mempunyai roh, seperti gunung, pohon besar, gua, dan lembah yang dalam. Benda-benda tertentu juga diyakini mempunyai kekuatan magis, kekuatan luar biasa yang dapat dimanfaatkan sesuai dengan keinginan pembaca mantra. Hal yang dinilai adalah mangkus (efektif) atau tidak mangkusnya mantra itu. Mantra yang mangkus akan membawa hasil nyata seperti yang diharapkan, misalnya orang yang dimantrai menjadi sembuh atau menjadi sakit. Di sini tidak timbul masalah indah atau tidak indah, yang penting adalah mangkus atau tidak.

Ahmadi (1986:145) menjelaskan mantra merupakan bagian dari magi yang memiliki tujuan: (a) produktif: (bertujuan menghasilkan, menambah kemakmuran, dan kebahagiaan seseorang); (b) protektif (bertujuan melindungi sesuatu dari hal-hal yang berbahaya atau merugikan); dan (c) destruktif (bertujuan menimbulkan kerusakan, kesusahan, dan bencana). Ahli lain, Amir (2013: 67-68) menyatakan mantra didaraskan atas permintaan seseorang, pendarasan itu mengandung niat yang praktis, seperti mengobati orang sakit, membuat orang lain sakit, untuk melariskan dagangan, atau melindungi diri dan rumah dari kekuatan jahat yang dikirim orang. Dalam beberapa kondisi, pendaras mantra (dukun, bomoh, orang pandai) ditakuti, bukan dihormati. Apalagi jika ia dikenal dengan mantra hitamnya (black magic). Pengamal mantra baik (white magic) lazimnya disegani dan dihormati.

Keberadaan mantra yang mencerminkan anismisme dan dinamisme masyarakat pemiliknya, serta keyakinan akan adanya benda tertentu yang mempunyai roh, seperti gunung, pohon besar, gua, dan lembah menjadi kajian yang layak disandingkan dengan paradigma ekologi.

Ekokritik (ecocritism) atau kritik ekologi sebenarnya bersumber dari pergerakan lingkungan modern sekitar tahun 1960-an di Eropa untuk menyikapi kondisi perubahan populasi. Dalam perjalanannya telaah ekologi tersebut dikaitkan dengan disiplin ilmu sastra sehingga melahirkan kajian ekologi sastra, sastra ekologis, atau ekokritik. Kajian interdisipliner ini cukup beralasan mengingat karya sastra tidak lahir dari sebuah kekosongan belaka. Teeuw (1988) mengemukakan bahwa sistem sastra tertentu tidak tumbuh dan berkembang dalam isolasi mutlak. Istilah ekokritik sendiri berasal dari bahasa Inggris, ecocritism, ecology dan critism. Ecology diartikan sebagai kajian ilmiahtentang pola hubungan-hubungan tumbuh-tumbuhan, hewan-hewan, dan manusia terhadap satu sama lain dan terhadap 
lingkungannya. Istilah critism (kritik) bermakna penilaian terhadap kualitas baik dan buruknya sebuah karya. Jadi ekokritik adalah kritik berwawasan lingkungan.

Ekokritik memiliki paradigma dasra setiap objek dapat dilihat dalam jaringan ekologis dan ekologi dapat dijadikan ilmu bantu dalam pendekatan kritik tersebut. Dalam konteks ekokritik Amerika, dikotomi opoisi binner alam dan budaya (nature-culture) telah berganti dengan model triade trikotomis nature-nurture-culture (alampemeliharaan-budaya) yang menegaskan bahwa jaringan ekologis membentuk keterkaitan antara alam, pemeliharaan, dan budaya dalam suatu ekoster, (Harsono: 2008: 34). dalam aras teori sastra teori ekokritik dapat dirunut dalam paradigma teori mimetik yang memiliki anggapan bahwa sastra memiliki keterkaitan dengan kenyataan. Didasarkan pada asumsi tersebutlah maka dalam tulisan ini sastra lisan mantra dapat dikaji dalam kaitannya dengan unsur-unsur ekologi yang ada dalam lingkungan nyata.

\section{METODOLOGI PENELITIAN}

Artikel ini merupakan hasil dari penelitian terhadap sastra lisan mantra yang bersifat kualitatif. Metode yang digunakan dalam olahan data penelitian adalah deskriptif analisis. Latar penelitian adalah daerah Belimbing yang termasuk ke dalam kelurahan Kuranji, Kecamatan Kuranji Kotamadya Padang, Provinsi Sumbar. Secara kependudukan kelurahan Kuranji yang berada di kecamatan Kuranji kotamadya Padang memiliki 25.679 jiwa yang tergabung ke dalam 6.013 kepala keluarga. Pada umumnya rata-rata pendidikan SMA. Entri penelitian adalah mantra pengobatan sakit gigi dengan fokus pada unsur-unsur ekologi yang terdapat dalam mantra pengobat sakit gigi serta unsur-unsur ekologi dalam konteks yang mensyarati kehadiran sastra lisan mantra pengobatan sakit gigi di Belimbing kelurahan Kuranji Kecamatan Kuranji kotamadya Padang.

Penelitian ini difokuskan pada, a) unsur-unsur ekologi dalam sastra lisan mantra pengobatan sakit gigi; b) unsurunsur ekologi yang melatari konteks kehadiran sastra lisan mantra pengobatan sakit gigi di Belimbing kelurahan Kuranji kecamatan Kuranji kotamadya Padang. Dalam proses penelitian, peneliti terlibat (participant observation) sehingga dapat memberikan dengan baik rasa saling percaya antara peneliti dengan sumber data (rapport). Informan yang dipilih sebanyak 3 orang dan berasal dari daerah di kelurahan Kuranji serta merupakan pelaku aktif mantra pengobatan sakit gigi di daerah setempat.

\section{HASIL DAN PEMBAHASAN}

Unsur-unsur Ekologi dalam Sastra Lisan Mantra Pengobatan Sakit Gigi

Masyarakat Belimbing Kelurahan Kuranji Kecamatan Kuranji Kotamadya Padang

Bismillahirrahmanirrahiim

Asa ulek dari banak

Asa banak dari ulek

Kalau angkau manggigik-gigik

Kalau angkau mancotok-cotok

Sadang insan manusia

Kalau angkau mancotok-cotok

Angkau kanai sumpah manjadi ampiang

Mati manggarebang

Mati dicakiak darah

Mati dicakiak tulang

Mati dicakiak dagiang

Ka teh indak bapucuak

Ka bawah indak baurek

Huuuu. ...Allah

Pada bait pertama dalam struktur mantra pengobatan sakit gigi tersebut ada empat aspek lingkungan alam penting yang muncul, yaitu a) tuhan; b) manusia; c) hewan; dan d) tumbuhan; Tuhan semesta alam. Inti dari segala kehidupan di atas bumi adalah Tuhan, Sang pencipta. Kehadiran manusia, hewan, dan tumbuh-tumbuhan adalah karena kekuatan dan kebesaran Tuhan, Allah SWT. Kenyataan itu adalah hal yang tidak dapat diingkati oleh siapapun. Kehidupan manusia, hewan, dan tumbuh-tumbuhan diatur oleh Allah SWT. Siklus kehidupan yang dimulai dari kelahiran, kecil, dewasa, tua, meninggal; sakit, sehat, semua diatur oleh Allah SWT. Oleh karena itu kewajiban manusia adalah menghadirkan Tuhan Sang Pencipta tersebut dalam setiap aktifitas ruang geraknya. Kalimat Bismillahirrahmaniirrahiim yang membuka mantra tersebut adalah penggambaran dari nature, alam, sesuatu yang alamiah, kenyataan yang tidak dapat dipungkiri, bahwa alam semesta dan segala isinya diatur oleh Tuhan Sang Pencipta. Oleh karena itu menjadi keharusan untuk memulai sesuatu pekerjaan dengan menyebut nama Allah SWT; dengan menyebut nama Allah, Yang Maha Pengasih, Maha Penyayang.

Sebagai makhluk ciptaan Tuhan, manusia juga harus menyadari dan mengerti bahwa segala sesuatu yang terjadi di alam semesta telah diatur oleh Allah SWT sebagai Sang pencipta. Pencitraan nurture asal muasal segala penyakit, asal muasal hewan, asal muasal tubuh manusia adalah dari Tuhan.

Pada larik-larik mantra yang berbunyi Asa ulek dari banak, Asa banak dari ulek, Kalau angkau manggigik-gigik, Kalau angkau mancotok-cotok, Sadang insan manusia dimunculkan kesadaran tentang organisme dalam ekosistem 
kehidupan serta perilaku organisme penghuni ekosistem tersebut. Organisme tersebut adalah hewan (ulek, ulat; banak), manusia (otak; bagian paling penting dalam tubuh manusia), dan manggigik-gigik, menggigit-gigit (aktifitas laku dari hewan dan manusia). Pada larik-larik ini si perapal mantra telah memberikan pemahaman kepada manusia tentang pencitraan dari nurture. Pencitraan tersebut adalah bahwa suatu penyakit (dalam konteks yang dimaksud disini adalah penyakit gigi) yang dialami oleh manusia adalah dari perilaku dan pikirannya. Asa ulek dari banak memberikan pemahaman nurture bahwa penyakit manusia (penyakit gigi dikonotasikan dengan ulat) asalnya adalah dari pikiran (otak) manusia itu sendiri. Sebaliknya asal muasal Banak (otak, pikiran) manusia adalah dari ulek (ulat, hewan). dalam larik-larik ini perapal mantra memberikan pemahaman tentang citra nurture-pengalaman manusia tentang sakit, sebuah penyakit adakalanya bersumber dari pola hidup, cara berpikir dan cara memperlakukan diri. Apabila manusia tidak menjaga kebersihan, maka penyakit gigi tersebut akan menggerogoti tubuhnya. Konotasi penyakit gigi dengan kata ulat adalah untuk menggambarkan sesuatu yang tidak bersih.

Kembali pada pencitraan nurture, dalam penagalaman kehidupan masyarakat tradisional masyarakat akrab dengan mitos bahwa penyakit gigi disebabkan oleh ulat. Pandangan ini bertahan sampai sekitar tahun 1700-an. Dalam kenyataannya ulat yang dimaksud tersebut adalah pembusukan yang terjadi pada gigi berlubang akibat pertemuan antara bakteri dan asam gula.

Pada bait kedua dan ketiga mantra tersebut memberikan penjelasan yang masih berkait dengan bait sebelumnya, yakni ulat sebagai penyebab penyakit gigi. Perapal mantra menyatakan jika kamu (ulat) mematuk-matuk (menimbulkan rasa sakit pada gigi) maka akan dikutuk menjadi emping (emping sebenarnya adalah makanan ringan dari hasil olahan buah melinjo). lebih lanjut dijelaskan bahwa jika kamu (ulat) terus mengganggu, menyebabkan penyakit, maka akan menemukan ajal dengan cara yang tidak menyenangkan (dicekik darah, daging, dan tulang). Dalam larik dan bait ini ditemukan unsur-unsur dari ekosistem alam semesta. Unsur tersebut adalah nature, tumbuhtumbuhan (emping, makanan yang terbuat dari buah melinjo), Pencipta alam semesta (Allah), serta pencitraan culture (mematuk-matuk).

Dalam kultur masyarakat tradisional Minangkabau pengobatan penyakit sudah menjadi sebuah tradisi, sebuah kultur, dengan memanfaatkan unsur-unsur dalam ekosistem alam. Tumbuh-tumbuhan dan hewan dipandang menjadi bagian tidak terpisahkan dari penyakit manusia, baik sebagai penyebab sakit, maupun sebagai pengobat penyakit. Selaras dengan hal itu kultur masyarakatnya membiasakan sebuah upaya pemeliharaan diri (nurture) melalui pengobatan. Dalam konteks masyarakat tradisional, pengobatan yang paling dianggap ampuh adalah kepada orang pintar (dukun). Biasanya orang pintar atau dukun tersebut dipandang memiliki kekuatan lebih dari masyarakat awam serta memiliki mantra sebagai sumber pengobatannya. Dalam larik-larik mantra pengobatan penyakit gigi tersebut memberikan citra tentang bagaimana manusia menyikapi alam, menyikapi diri dan tubuhnya melalui serangkaian pengobatan, pemeliharaan agar terhindar dari penyakit tertentu. Mitos tentang ulat sebagai sumber penyakit gigi mencitrakan bahwa antara manusia dan hewan memiliki hubungan yang erat, bisa dalam konteks merugikan, bisa dalam konteks menguntungkan.

\section{Unsur-unsur Ekologi yang Melatari Konteks Kehadiran Mantra Pengobatan Sakit Gigi Masyarakat Belimbing Kelurahan Kuranji Kecamatan Kuranji Kotamadya Padang}

Berdasarkan hasil wawancara dengan 3 orang informan, ketiganya menyatakan pengobatan dengan mantra untuk penyakit gigi harus dilengkapi dengan persyaratan sesuai dengan permintaan dukun. Informan 1 (Saban, 52 tahun) mensyaratkan pelengkap pengobatan dengan mantra penyakit gigi adalah rokok 1 bungku (digunakan untuk pengobatan awal). Rokok diyakini akan dapat membakar ulat yang bersarang dalam gigi yang si sakit. Syarat berikutnya adalah daun sitawa-daun sidingin (daun cocor bebek), umbut pisang (batang pisang yang masih muda), sekapur sirih, kemenyan, daun siamih, gambir, kapur sirih, dan air putih. Dedauan dari tumbuh-tumbuhan tersebut akan dipotong-potong dan di iris kecil, dimasukkan ke dalam air putih dan air rendaman daunan trsebut harus diminum oleh si sakit setelah dimantrai dukun.
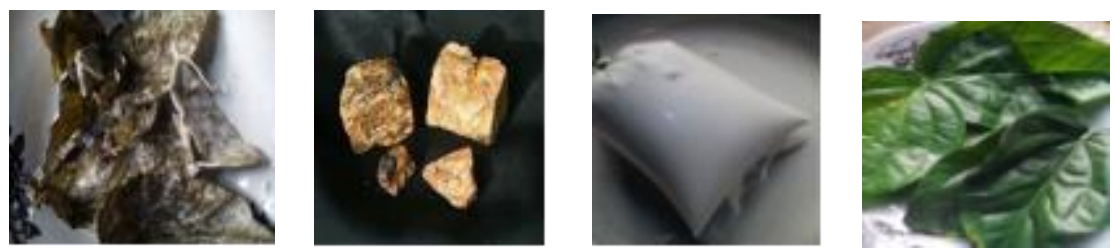

Gambar 1, 2, 3. 4 daun gambir, kemenyan, kapur sirih, daun sirih

Dalam pengobatan sakit gigi dengan mantra, kemenyan digunakan sebagai perantara pada saat dukun membacakan mantra. Kemenyan akan dibakar pada saat pembacaan mantra dimulai. Sementara daun sirih, gambir, pinang dan kapur sirih digunakan oleh dukun untuk dimantrai. Daun-daun dan kapur sirih yang telah dimantrai tersebut harus dijadikan satu dan dikunyah oleh si sakit. Air kunyahan tersebut harus ditelan dan sepah sirih boleh dibuang. Air kunyahan sirih yang berwarna merah tersebut juga dapa dioleskan pada bagian gigi yang mengalami sakit.

Dalam bidang ilmu Biologi dan pengobatan dijelaskan bahwa Sirih (Piper Bitle) merupakan tumbuhan yang digunakan sebagai obat-obatan antioksidan warisan turun temurun sejak masih nenek moyang. Daun sirih memiiki minyak atsiri, minyak terbang, seskuiterpen, pati, diatase, gula dan zat samak dan kavikol yang memiliki daya mematikan kuman, antioksidasi dan fungisida, anti jamur. Tumbuhan ini diyakini berkhasiat menghilangkan bau badan, bersifat menahan perdarahan, menyembuhkan luka pada kulit, dan gangguan saluran pencernaan. 


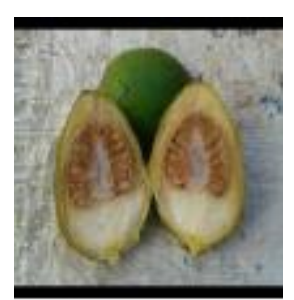

\section{Gambar 5. Pinang (Areca Catechu)}

Menurut penuturan informan, Pinang (Areca catechu) digunakan secara turun temurun oleh masyarakat di daerah Belimbing sebagai campuran dalam mengunyah sirih. Dalam pengobatan sakit dengan mantra biji pinang digunakan bersama dengan gambir, sirih dan kapur sirih. Pinang yang dipilih haruslah yang telah dikupas dan dibuang kulitnya, kemudian buah Pinang tersebut dipecah menjadi bagian kecil untuk dikunyah bersama daun Sirih, Gambir, dan kapur sirih.
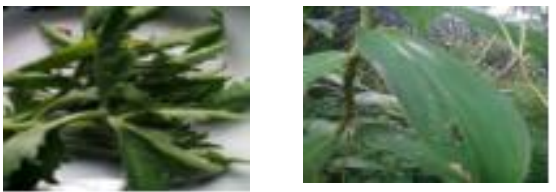

\section{Gambar 6,7. Daun Cocor Bebek (Daun Sitawa- daun sidingin)}

Secara citra culture pada masyarakat Minangkabau tradsional, dau cocor bebek dikenal dengan nama daun Sitawa-Sidingin. Kedua daun ini selalu digunakan secara bersamaan untuk mengobati berbagai penyakit. Sementara dalam bidang biologi daun cocor bebek atau daun suru bebek memiliki nama Latin Kalanchoe pinnata syn, briophyllum calychinum. Cocor bebek mengandung apperzuur, damar, zat lendir, magnesium malat, kalsium oksalat, asam formiat, dan tannin yang berkhasiat untuk menyembuhkan sakit kepala, panas dalam, luka, demam, sakit dada, serta penyakit kulit. Sitawa atau dalam bahasa latinnya Andrographis Paniculata juga termasuk spesies cocok bebek, memiliki kandungan apperzuur, damar, zat lendir, magnesium malat, kalsium oksalat, asam formiat, dan tannin yang berkhasiat untuk menyembuhkan panas dalam dan rasa sakit akibat peradangan.

Oleh informan kedua (Inur, 45 tahun) pengobatan sakit gigi dengan mantra hanya mensyaratkan pelengkap yaitu umbut pisang (batang pisang yang masih muda dan lunak). Umbuik Pisang (Umbut Pisang atau batang pisang muda yang masih lunak) fungsinya untuk menurunkan panas. Umbut Pisang yang diambil adalah pada bagian pangkalnya, dan diambil pada bagian isi tengahnya, supaya banyak getahnya. Semua ramuan tersebut diiris-iris, kemudian dicampurkan ke dalam air lalu dibacakan mantra oleh dukun. Air ramuan yang telah dibacakan mantra kemudian dikumur-kumur oleh si sakit. Dalam bidang Biologi diketahui beberapa jeni spesies Pisang, seperti Musa Acuminata, $\underline{M}$. Balbisiana, dan M. Paradisiaca.

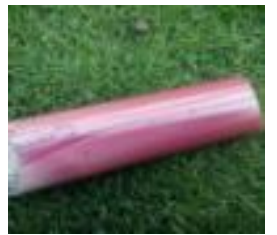

Gambar 8. Umbut Pisang (umbuik pisang atau batang pisang muda)

Informan III (Upik Manih, 50 tahun), menggunakan syarat perlengkapan yang sederhana dalam pengobatan sakit gigi dengan mantra. Syarat pelengkap adalah Daun Siamih. Upik Manih menjelaskan Siamih merupakan sejenis rerumputan yang tumbuh di tengah sawah, dipercaya masyarakat dapat menyembuhkan berbagai macam penyakit, seperti luka, penyakit magh dan sakit gigi. Daun Siamih digunakan oleh Upik Manih untuk mengobati pasiennya dengan cara direbus. Air rebusan tersebut dikumur-kumur oleh pasien. Air rebusan daun siamih terasa asam, oleh sebab itu, bisa membantu membunuh kuman pada bagian gigi pasien yang sakit.

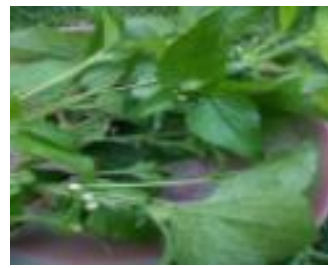

\section{Gambar 9. daun Siamih (daun Beluntas)}

Syarat pelengkap terakhir dalam pengobatan sakit gigi dengan mantra yang harus dipenuhi oleh si sakit adalah air putih. Dukun akan meminta si sakit membawakan air putih yang akan digunakan pada saat proses pengobatan dengan mantra dilakukan. Setelah semua ramuan daun-daunan selesai dipotong dan diiris, dukun akan memasukkan ke dalam air putih yang telah disediakan tersebut. Air putih yang disiapkan si sakit harus air putih yang berasal dari sungai yang jernih, air yang mengalir, bukan air sumur atau air tidak mengalir. Ada keyakinan yang dimiliki masyarakat di 
Belimbing bahwa air yang mengalir di sungai bersumber dari mata air yang bersih, murni, dan belum mengandung zatzat kimia yang membuat kekuatan mantra dan ramuan menjadi hilang.

Munculnya unsur-unsur ekologi dalam sastra lisan mantra pengobatan sakit gigi di daerah Belimbing Kelurahan Kuranji Kota Padang menunjukkan kuatnya ketergantungan antara lingkungan dengan manusia. Pencitraan nature melalui daun Cocor Bebek, daun Sirih, air putih, daun beluntas merupakan penguatan tentang keberadaan kehidupan manusia dalam kondisi sehat ataupun sakit tidak bisa terlepas dari organisme makhluk hidup lainnya. Pencitraan culture pengobatan sakit gigi dengan mantra serta pencitraan nurture melalui proses pemanfaatan serta peramuan obat-obatan-daun Cocor bebek, batang Pisang muda dipotong-potong, dicincang, dan direndam bersama air putih merupakan penguatan tentang pelestarian sumber-sumber daya alam hayati untuk keberlangsungan kehidupan manusia. Habitat produktif di lingkungan alam memberikan manfaat untuk kesehatan tubuh manusia. Hal ini menunjukkan adanya keharmonisan antara organisme yang menghuni ekosistem besar di alam sebagai ciptaan Tuhan yang perlu dijaga dan dilestarikan.

\section{PENUTUP}

Sastra lisan mantra pengobatan penyakit gigi pernah tumbuh dan berkembang dalam lingkungan kehidupan masyarakat di desan Belimbing Kelurahan Kuranji Kotamadya Padang. Sebagai bagian dari suku bangsa Minangkabau yang kaya akan tradisi dan kebudayaan, sastra lisan mantra di daerah Belimbing telah menjadi bagian tidak terpisahkan dari gerak laku kehidupan masyarakatnya. Dalam praktiknya, sastra lisan mantra ini selalu bersentuha dengan sumbersumber hayati, penghuni ekosistem di lingkungan alam daerah tersebut. Dalam praktik pengobatan mantra ini dukun yang berperan sebagai pengobat si sakit telah menjembatani pencitraan nature, nurture, dan culture yang sangat kuat dari masyarakat setempat. Pengobatan dengan mantra tersebut telah menegaskan bahwa antara alam beserta isinya memiliki hubungan ketergantungan yang mendukung keberlangsungan kehidupan manusia dan sebaliknya. Perubahan kondisi alam dan geografis akibat teknologi baru sekiranya perlu diberi perhatian serius oleh masyarakat, termasuk di daerah Belimbing. Perubahan kondisi alam dan geografis akibat teknologi baru secara pelan akan mengikis keberlangsungan hidup ekosistem hayati yang secara tidak langsun juga berdampak pada keberlangsungan kehidupan manusia. Melalui kajian interdisipliner ekologi dan karya sastra upaya penelusuran kondisi alam, upaya pelestarian dan pemanfaatannya menjadi bagian yang penting untuk dilakukan.

\section{KEPUSTAKAAN}

Ahmadi, Abu. 1986. Antropologi Budaya. Surabaya: CV Pelangi.

Amir, Adriyetti. 2013. Sastra Lisan Indonesia. Yogyakarta: CV Andi Offset.

Teeuw. A. 1988. Sastra dan Ilmu Sastra. Jakarta. PT Girimukti Pasaka.

Djamaris, Edwar. 2002. Pengantar Sastra Rakyat Minangkabau. Jakarta: Obor Indonesia.

Endraswara, Suwardi. 2016. Ekologi Sastra; Konsep, Langkah, dan Penerapan. Jakarta. Penerbit CAPS.

Harsono, Siswo. "Ekokritik: Kritik Sastra Berwawasan Lingkungan". Artikel. Jurnal kajian Sastra Vol. 32 No. 12008. http://e-journal.undip.ac.id/index.php/ kajiansastra/article/view/2702. download 25 September 2017.

Kaswadi. (2015). "Paradigma Ekologi dalam Kajian Sastra". Artikel. Jurnal Paramasastra Vol. 2 No. 2 tahun 2015. http://e-journal.fbs.unes.ac.id/index.php/ paramasastra/article/download/35/40. download tanggal 26 september 2017 